\title{
DEFINIÇÕES E PRINCÍPIOS PARA UMA EDUCAÇÃO AMBIENTAL EFETIVA
}

Aparecida Dias de Macedo ${ }^{1}$

Ariane Delprete Faria ${ }^{2}$

\section{RESUMO}

Este estudo discorre sobre conceitos, diretrizes, princípios e objetivos da Educação Ambiental. Seu objetivo consiste em apontar conceitos da Educação Ambiental e analisar seus princípios, objetivos e diretrizes a fim de compreender o cenário atual para uma efetiva Educação Ambiental. Para o tal, realizou-se um levantamento bibliográfico para obter as informações necessárias para a concretização da mesma. Os princípios e objetivos para o desenvolvimento e prática da Educação no país, bem como os de diversos documentos com princípios e objetivos afins, discorrem em frases bem elaboradas, cerca todos os pontos necessários para que de fato a Educação Ambiental aconteça de forma efetiva no país, porém, muitos pontos demonstram-se fora da realidade socioeducacional brasileira, pois muitos itens ainda não estão presentes na realidade das instituições educativas, além do despreparo do profissional. Esse fato é preocupante porque existem princípios e objetivos a serem alcançados, porém os passos para a efetivação dos mesmos é lento.

Palavras chave: Educação, Educação Ambiental, Meio Ambiente.

\section{ABSTRACT}

This study discusses concepts, guidelines, principles and objectives for an effective and transformative Environmental Education, so that the human being is understood as an integral part of the environment. The objective of this work is to point out concepts of Environmental Education and analyze its principles, objectives and guidelines in order to understand the current scenario for an effective Environmental Education. For this, a bibliographic survey was carried out to obtain the necessary information for the accomplishment of the same. The principles and objectives for the development and practice of Education in the country, as well as those of several documents with principles and related objectives, elaborate in well-written phrases, surround all the necessary points so that Environmental Education actually happens in an effective way in the country, however, many points are demonstrated outside the Brazilian socio-educational reality, since many items are not yet present in the reality of educational institutions, besides the unpreparedness of the professional. This fact

\footnotetext{
${ }^{1}$ Graduada em Licenciatura Plena em Matemática pela Faculdade de Filosofia, Ciências e Letras de Alegre, graduada em Licenciatura Plena em Geografia pela Universidade Metropolitana de Santos, especialista Lato sensu em Matemática pela Faculdades Integradas de Jacarepaguá, aluna do curso de Mestrado pela Facultad Interamericana de CiènciasSociales- FICS, atua como professora na rede municipal de Muniz Freire.

${ }^{2}$ Graduada em Licenciatura Plena em Ciências Biológicas pela Faculdade de Filosofia, Ciências e Letras de Alegre, especialista Lato sensu em Educação Ambiental e Recursos Naturais pela Faculdade de Ciências e Letras de Alegre, especialista em Ciências Biológicas pela Faculdade do Noroeste de Minas (FINOM), aluna do curso de Mestrado Scricto Sensu pelo Institute of Tecnology Education e Health, atua como professora na rede municipal de Muniz Freire.
} 
is worrisome because there are principles and goals to be achieved, but the steps to achieve them are slow.

Keywords: Education, Environmental Education, Environment.

\section{RESUMEN}

Este estudio discurre sobre conceptos, directrices, principios y objetivos para una efectiva y transformadora Educación Ambiental, a fin de que el ser humano se comprenda como parte integrante del ambiente. El objetivo de este trabajo consiste en apuntar conceptos de la Educación Ambiental y analizar sus principios, objetivos y directrices a fin de comprender el escenario actual para una efectiva Educación Ambiental. Para ello, se realizó un levantamiento bibliográfico para obtener las informaciones necesarias para la concreción de la misma. Los principios y objetivos para el desarrollo y práctica de la Educación en el país, así como los de diversos documentos con principios y objetivos afines, discurren en frases bien elaboradas, cerca de todos los puntos necesarios para que de hecho la Educación Ambiental ocurra de forma efectiva en el país sin embargo, muchos puntos se demuestran fuera de la realidad socioeducativa brasileña, pues muchos ítems aún no están presentes en la realidad de las instituciones educativas, además del despreparo del profesional. Este hecho es preocupante porque existen principios y objetivos a ser alcanzados, pero los pasos para la efectividad de los mismos es lento.

Palabras clave: Educación, Educación Ambiental,

\section{INTRODUÇÃO}

Questões ambientais como aumento do efeito estufa, aquecimento global, mudanças climáticas, extinção de espécies e catástrofes ambientais são pauta constantes da mídia no intuito de sensibilizar a população sobre as conseqüências desses desequilíbrios para a vida no Planeta Terra. Compreendemos que o ser humano está inserido no ambiente e que a forma de vida sociopolítica que se insere altera o meio ambiente de todas as formas.

Precisamos incentivar a que os alunos, mediante a efetiva educação ambiental que se almeja, percebam-se parte desse meio; que suas ações contribuem para a degradação ambiental e que é preciso ter uma nova postura não somente nas atitudes individuais do cotidiano, mas, ainda, uma mudança efetiva quanto às relações sociais, 
políticas, econômicas e históricas, partindo do individual para uma ação conjunta entre sociedade e políticas públicas.

Diante dessa necessidade os conceitos, princípios, objetivos e diretrizes da Educação Ambiental estão adequados a realidade educacional vigente em nosso país?

Portanto, o objetivo deste trabalho consiste em apontar conceitos da Educação Ambiental e analisar seus princípios, objetivos e diretrizes a fim de compreender o cenário atual para uma efetiva Educação Ambiental.

Para alcançar esse objetivo, foi realizado um levantamento bibliográfico visando obter as informações a respeito do tema. O referencial teórico, primeiramente, buscou conceituar o termo educar. Em seguida definir o termo Educação Ambiental para uma melhor compreensão da sua relação com a educação escolar. No terceiro capítulo, buscou-se analisar as diretrizes, os princípios e objetivos da Educação Ambiental conforme a Lei n 9795 e o Programa Nacional de Educação Ambiental (ProNEA).

\section{0 "EDUCAR"}

Para definir a Educação Ambiental, primeiramente faz-se necessário buscar o significado da palavra "Educação". A Enciclopédia Barsa (2002, p. 298) descreve a Educação como aquela que "aumenta o poder do homem sobre a natureza e, ao mesmo tempo, busca conformá-lo aos objetivos de progresso e equilíbrio social da coletividade a que pertence." O que nos faz pensar que deste ponto de vista, como afirma Furtado (2009, p.339), em "certo discurso de caráter antropocêntrico", onde a educação torna-se uma ferramenta para o crescimento do "status" do ser humano, sem levar em conta as preocupações com o meio em que ele está inserido.

No dicionário Aurélio o conceito de Educação está ligado ao ato de "adestrar" e "criar" animais, cultivar plantas e, por meio da aplicação de métodos, o indivíduo adquirir dotes físicos, morais e intelectuais. A partir do real significado da palavra entende-se, que do ponto de vista do ser humano, a educação está atrelada a um conjunto de conhecimentos e saberes transmitidos e assimilados a fim de padronizar, "adestrar" para viver em sociedade. Portanto, entende-se que o nível de educação de um indivíduo está associado ao grau de conhecimento que ele possui. 
Mas, para Loureiro (2004, p.17), ao ato de educar vai além de conhecimentos adquiridos para adestrar uma sociedade, educar

(...) é transformar pela teoria em confronto com a prática e vice-versa (práxis), com consciência adquirida na relação entre o eu e o outro, nós (em sociedade) e o mundo. É desvelar a realidade e trabalhar com os sujeitos concretos, situados espacial e historicamente. É, portanto, exercer a autonomia para uma vida plena, modificando-nos individualmente pela ação conjunta que nos conduz às transformações estruturais.

Guimarães no livro intitulado "A formação de educadores ambientais" (2007, p.138) afirma que a "educação não é apenas a reprodução de conhecimentos, mas a produção de conhecimentos, novos caminhos e novas relações entre a sociedade e natureza." Essa reflexão nos remete a pensar na relação ensino/ aprendizagem através da pesquisa, que nos leva a ação e consequentemente a uma transformação de si próprio e do que está a nossa volta. "A partir da construção e reconstrução do conhecimento os atores são motivados a participar ativamente do processo de transformação da sociedade, exercendo a cidadania." (LEITE; SILVA, 2008, P. 384)

Gadotti (2000, p.2) em seu trabalho intitulado "Saber aprender: um olhar sobre Paulo Freire e as perspectivas atuais da educação", descreve o educar a partir das pedagogias de Paulo Freire. Neste trabalho destaco a afirmativa de que "educar é conhecer, é ler o mundo, para poder transformá-lo". Para educar, primeiramente, é preciso conhecer o mundo, fazer uma leitura dele, apropriar-se, ser um eterno aprendiz e a partir dessa leitura de mundo agir para transformá-lo, explicando claramente a figura acima. Afirma que para Paulo Freire "jamais um educador poderia ser arrogante." Segundo ele, além de ler o mundo é preciso compartilhar a leitura do mundo lido. "Só posso saber se minha leitura de mundo está correta a não ser que a compare com a leitura do mundo de outras pessoas". (GADOTTI, 2000, p.3)

Destaca também a educação como "ato de produção e de reconstrução do saber" afirmando que "conhecer não é acumular conhecimentos, informações ou dados. Conhecer implica mudança de atitudes, saber pensar e não apenas assimilar conteúdos escolares do saber chamado universal".

Necessitamos sempre nos reeducar no sentido de compreender como ser integrante deste mundo, tarefa difícil, mas necessária se quisermos continuar a escrever a nossa história. 
Perceber, sentir, interpretar, conhecer, agir e integrar, em constante transformação, são dimensões conexas da educação e fins de auto realização. Mudar e mudar-se simultaneamente é a unidade complexa da nossa espécie, no constante tornar-se/formar-se na história, finalidade e condição inerentes à nossa natureza enquanto ser biológico e vivendo em sociedade (LOUREIRO, 2003, apud LOUREIRO, 2004, p. 19).

No entanto, "saber em educação é mudar de forma, criar a forma, formarse. Educar-se é formar-se", "enfrentar as incertezas" diante de um mundo recheado se surpresas, "imprevistos" e "incerto". (GADOTTI, 2000)

O "educar" torna-se tarefa diária e contínua, um reeducar-se todos os dias, um repensar das ações cotidianas e as consequências que elas trazem consigo na tentativa de viver da melhor maneira possível.

\section{EDUCAÇÃO AMBIENTAL: CONCEITOS E DEFINIÇÕES}

Em se tratando do termo Educação, surge uma segunda palavra, Ambiental.

Mas para muitos sempre volta à tona a questão que, como cita Carvalho (2004, p.17), não existe o termo Educação Ambiental, pois toda educação é ambiental. O que nos faz pensar se toda educação é ambiental porque ela é insustentável, como afirma Layrargues? Percebemos o fato de muitos ainda pensarem em uma educação hegemônica, que privilegia setores e classes, e incapaz de questionar a realidade social, cultural e política atrelada à ambiental. Confirmando,

Trata-se do velho argumento de que "toda educação é ambiental, assim, toda educação ambiental é simplesmente, educação". Este tipo de argumento parece apenas jogar água fria no que ao longo dos anos tem se tentado construir como uma especificidade da prática educativa ambientalmente orientada para diluí-la no marco geral da educação. (CARVALHO, 2004, p.17)

"Jogar água fria" no termo Educação Ambiental realmente é jogar fora décadas de estudos, saberes e ações já construídas durante esse tempo. E se existe o termo é porque de fato antes a educação não era pensada ambientalmente.

E contrapartida, de acordo com Guimarães a "palavra ambiental" é apenas adjetiva no termo Educação Ambiental (EA), "qualifica o processo educacional". "Desta forma "percebe-se que a Educação Ambiental se estabelece hoje como uma nova dimensão da educação." (GUIMARÃES, 2007, p. 16) E nessa relação entre educação e ambiente os envolvidos no processo passam a buscar e ter conhecimentos sobre as questões ambientais tornando-se mais preocupados e 
engajados na conservação do meio ambiente buscando alternativas para se viver melhor.

Como dizem Layrargues e Lima (2011)

A Educação Ambiental surgiu no contexto de emergência de uma crise ambiental reconhecida nas décadas finais do século XX e estruturou-se como fruto de uma demanda para que o ser humano adotasse uma visão de mundo e uma prática social capazes de minimizar os impactos ambientais então prevalecentes. (LAYRARGUES; LIMA, 2011, p.5)

No mesmo pensamento Layrargues (2004), na apresentação do livro "Identidades da educação ambiental brasileira", descreve o termo Educação Ambiental como um "composto formado por um substantivo e um adjetivo", onde o substantivo define a prática educativa e o adjetivo "ambiental" define o contexto dessa prática, "diante desta crise ambiental que ora o mundo vivencia." Segundo, ele a educação e os demais sistemas sociais não tem sido sustentáveis o que faz necessário sua reformulação.

Assim, para Layrargues (2004, p. 7) "Educação Ambiental" designa uma qualidade especial que define uma classe de características que juntas, permitem o reconhecimento de sua identidade, diante de uma Educação que antes não era ambiental. E que se "configura crescentemente como uma questão que envolve um conjunto de atores do universo educativo" (...), como diz Jacobi (2004, p. 29).

Vários autores definem o significado do termo Educação Ambiental. Marcatto explicita

(...) formar uma população mundial consciente e preocupada com o ambiente e com os problemas que lhe dizem respeito, uma população que tenha os conhecimentos, as competências, o estado de espírito, as motivações e o sentido de participação e engajamento que lhe permita trabalhar individualmente e coletivamente para resolver os problemas atuais e impedir que se repitam (...)(SEARA FILHO, 1987 Apud MARCATTO, 2002, p. 14).

A partir deste ponto de vista percebemos a importância de se incluir como parte integrante do meio ambiente. Que pratiquemos a educação ambiental porque compreendemos sermos uma parte desse todo, não somente o meio físico, mas o meio em que vivemos: nossa casa, escola, bairro, cidade...

Como diz Ruiz et AL (2005, p. 32) "(...) O homem interfere na natureza com sua consciência, conhecimentos, atitudes, habilidades e formas de participar na sociedade; nasce, cresce e morre sem saber tudo sobre o ambiente em que vive." 
Então, quando se refere à Educação Ambiental é preciso atrelar o seu conceito a nossa própria vida e das relações com todos os seres vivos e os elementos do planeta, sendo assim

Falar de educação ambiental é falar da própria vida e de seus relacionamentos com paradigmas que incluem respeito e reverência por todos os seres da Terra. É levantar questões, refletir sobre causas e efeitos, buscar soluções, encorajar participação, fortalecer indivíduos e grupos para que cada um se sinta apto, motivado e responsável a tornar esse um mundo melhor. (MARCATTO, 2002, p. 4)

Ao definir o conceito de ecossistema, entende-se que o ecossistema é o conjunto de seres bióticos e abióticos de um determinado local relacionando entre si e com meio. Pensando nesse conceito, se o ser humano se relaciona com meio abiótico ele está inserido nesse ecossistema. Mas, de acordo com Guimarães (2007), ao longo do processo evolutivo o ser humano foi se individualizando e se isolando dessa pertença ao meio ambiente, no sentido de dominar a natureza sem pensar nas consequências dessa dominação hegemônica.

Guimarães (2007, p. 21) refere à EA como um "fenômeno recente" que surge em resposta a crise ambiental instaurada e conhecida pelo mundo.

Sendo assim

EA apresenta uma nova dimensão a ser incorporada ao processo educacional, trazendo toda uma recente discussão sobre as questões ambientais, e as consequentes transformações de conhecimento, valores e atitudes diante de uma nova realidade a ser construída. (GUIMARÃ ES, 2007, p. 9)

Em seu livro intitulado "Educação ambiental: no consenso um embate?", Guimarães demonstra através de depoimentos coletados de uma pesquisa realizada entre alunos de graduação em diferentes cursos de licenciatura que a maioria deles pensava a "Educação Ambiental como um processo de formação comportamental do indivíduo em relação à natureza. Como se a soma desses comportamentos individuais é que se desse a transformação da sociedade." (GUIMARÃES, 2007, p. 38)

Segundo ele, esse tipo de abordagem da educação ambiental não leva em conta as questões sociais e políticas, tomando para o indivíduo a responsabilidade dos problemas ambientais e a busca de soluções.

A Educação Ambiental proposta/consentida por segmentos dominantes da sociedade, tenta velar a divisão social de classes ao conferir o indivíduo a culpabilidade e a responsabilidade de buscar soluções para os problemas ambientais, sem entrar (...) no mérito das relações sociais de poder que produziram historicamente aquele contexto. (GUIMARÃES, 2007, p. 46) 
Neste contexto a EA torna-se ferramenta crucial para a sensibilização e tomada de consciência da população sobre os problemas ambientais e o despertar urgente de "nos debruçar sobre eles". (MARCATTO, 2002, p. 12)

Como diz Loureiro (2003, p. 46) a falta de percepção da Educação Ambiental como um "processo educativo" ao longo da história, fez com que ela fosse trabalhada de forma descontextualizada, com ações voltadas para preservação do meio ambiente "físico" sem levar em conta as "questões sociais e princípios básicos da educação". Dessa forma, precisamos compreender que a Educação ambiental não deve ser trabalhada de forma isolada, fora do contexto social, histórico e político, mas deve levar ao indivíduo a perceber-se parte integrante desse meio, capaz de agir individualmente, pensando coletivamente de forma contextualizada com o meio que está inserido na busca de mudanças concretas e efetivas.

\begin{abstract}
A Educação Ambiental é um processo participativo, onde as pessoas podem assumir o papel de elemento central do processo, participando ativamente no diagnóstico dos problemas e busca de soluções, sendo preparadas como agentes transformadores, por meio de desenvolvimento de habilidades e formação de atitudes, através de uma conduta ética e condizente ao exercício da cidadania. (RUIZ et al, 2005, p.32)
\end{abstract}

E nessa lógica do indivíduo assumir seu papel participativo no diagnóstico e resolução de problemas, sendo um agente transformador, que não vise somente à mudança de realidade ecológica na defesa da fauna e da flora, mas que seja um cidadão crítico na busca de melhores condições de vida, do meio em que vivem. $\mathrm{E}$ segundo Ruiz et al (2005) sem se preocupar em achar "culpados ou responsáveis pelos problemas ambientais", mas agir para uma melhor qualidade de vida.

No documento da Secretaria de Meio Ambiente de São Paulo intitulado "Conceitos para se fazer Educação Ambiental" $(1999$, p.6) me chamou a atenção as definições de Educação Ambiental propostas pelo ecologista americano Garrett Hardin. Segundo ele

- A Educação Ambiental prepara as pessoas para a vida enquanto pertencentes à biosfera;

- Educação Ambiental é o aprendizado para compreender, apreciar, saber lidar e manter os sistemas ambientais na sua totalidade.

- Educação Ambiental significa aprender a ver um problema específico e questionar o seu histórico, os fatores econômicos, 
tecnológicos, os fenômenos naturais ou artificiais causador do problema e as sugestões de ações para saná-lo.

- Educação Ambiental é a aprendizagem de como gerenciar e melhorar as relações entre a sociedade humana e o ambiente, de modo integrado e sustentável;

- A Educação Ambiental significa aprender a empregar novas tecnologias, aumentar a produtividade, evitar desastres ambientais, minorar os danos existentes, conhecer e utilizar novas oportunidades e tomar decisões.

Importantes definições que narram toda a função de Educação Ambiental para aquele que definitivamente se preocupa em tratá-la de forma séria e engajada na mudança efetiva da realidade da biosfera.

Guimarães (2007, p.138-139) compara a educação com o fluxo de um rio e a educação ambiental é a contra correnteza desse rio para que possamos mudar o seu curso. Nesse contexto, segundo ele, não adianta criarmos correntezas fora do rio, precisamos estar inseridos na educação para que possamos construir ações transformadoras da realidade social, contribuindo na superação de problemas ambientais, gerando movimento, impulsionando e potencializando o processo de transformação.

\section{DIRETRIZES, PRINCíPIOS E OBJETIVOS DA EDUCAÇÃO AMBIENTAL CONFORME A LEI N 9795 E O PROGRAMA NACIONAL DE EDUCAÇÃO AMBIENTAL (PRONEA)}

A partir da Conferência de Tbilisi, 1977, preocupados com a situação do meio ambiente de uma forma geral, foram estabelecidos marcos legais que garantissem o cumprimento da Educação Ambiental como educadora e transformadora para uma sociedade ativa e participante.

A constituição Federal no Art.225, do Capítulo VI que trata do meio ambiente, assegura que "todos tem direito ao meio ambiente ecologicamente equilibrado, bem de uso comum do povo e essencial à sadia qualidade de vida, impondo-se ao poder público e à coletividade o dever de defendê-lo e preservá-lo para as presentes e futuras gerações." 
A Lei N 9795 de 27 de abril de 1999, considerada de acordo com Marcatto (2002) a "mais recente e mais importante lei de Educação Ambiental do país" que "dispõe sobre a educação ambiental, institui a Política Nacional de Educação Ambiental e dá outras providências"

Sendo assim, em consonância com a Lei 9795/99, o ProNEA (Programa Nacional de Educação Ambiental) (2014, p. 23) cujas "ações destinam-se a assegurar, no âmbito educativo, a interação e a integração equilibradas das múltiplas dimensões da sustentabilidade ambiental - ecológica, social, ética, cultural, econômica, espacial e política - ao desenvolvimento do país, buscando o envolvimento e a participação social na proteção, recuperação e melhoria das condições ambientais e de qualidade de vida" assume as seguintes diretrizes:

- Transversalidade e Interdisciplinaridade.

- Descentralização Espacial e Institucional.

- Sustentabilidade Socioambiental.

- Democracia e Participação Social.

- Aperfeiçoamento e Fortalecimento dos Sistemas de Ensino, Meio Ambiente e outros que tenham interface com a educação ambiental.

No Art. 4º da Lei 9795/99 descreve os princípios da Educação Ambiental, dentre eles:

- Concepção de ambiente em sua totalidade, considerando a interdependência sistêmica entre o meio natural e o construído, o socioeconômico e o cultural, o físico e o espiritual, sob o enfoque da sustentabilidade.

- Reconhecimento da diversidade cultural, étnica, racial, genética, de espécies e de ecossistemas.

- Enfoque humanista, histórico, crítico, político, democrático, participativo, inclusivo, dialógico, cooperativo e emancipatório.

- Compromisso com a cidadania ambiental.

- Vinculação entre as diferentes dimensões do conhecimento; entre os valores éticos e estéticos; entre a educação, o trabalho, a cultura e as práticas sociais.

- Pluralismo de ideias e concepções pedagógicas.

- Garantia de continuidade e permanência do processo educativo.

- Permanente avaliação crítica e construtiva do processo educativo.

- Coerência entre o pensar, o falar, o sentir e o fazer. 
No documento ProNEA (2014, p. 25-26) os princípios da Educação Ambiental são:

- Concepção de ambiente em sua totalidade, considerando a interdependência sistêmica entre o meio natural e o construído, o socioeconômico e o cultural, o físico e o espiritual, sob o enfoque da sustentabilidade.

- Abordagem articulada das questões ambientais locais, regionais, nacionais, transfronteiriças e globais.

- Respeito à liberdade e à equidade de gênero.

- Reconhecimento da diversidade cultural, étnica, racial, genética, de espécies e de ecossistemas.

- Enfoque humanista, histórico, crítico, político, democrático, participativo, inclusivo, dialógico, cooperativo e emancipatório.

- Compromisso com a cidadania ambiental.

- Vinculação entre as diferentes dimensões do conhecimento; entre os valores éticos e estéticos; entre a educação, o trabalho, a cultura e as práticas sociais.

- Democratização na produção e divulgação do conhecimento e fomento à interatividade na informação.

- Pluralismo de ideias e concepções pedagógicas.

- Garantia de continuidade e permanência do processo educativo.

- Permanente avaliação crítica e construtiva do processo educativo.

- Coerência entre o pensar, o falar, o sentir e o fazer.

- Transparência.

A Lei 9795 de 27 de abril de 1999 em seu Art. 5o e o ProNEA também descrevem os objetivos da educação ambiental.

Segundo a referida Lei dentre os objetivos da Educação Ambiental, destaco:

- o desenvolvimento de uma compreensão integrada do meio ambiente em suas múltiplas e complexas relações, envolvendo aspectos ecológicos, psicológicos, legais, políticos, sociais, econômicos, científicos, culturais e éticos.

- o estímulo e o fortalecimento de uma consciência crítica sobre a problemática ambiental e social;

- o incentivo à participação individual e coletiva, permanente e responsável, na preservação do equilíbrio do meio ambiente, entendendo-se a defesa da qualidade ambiental como um valor inseparável do exercício da cidadania; 
No ProNEA, destaco os seguintes objetivos da EA:

- Promover processos de educação ambiental voltados para valores humanistas, conhecimentos, habilidades, atitudes e competências que contribuam para a participação cidadã na construção de sociedades sustentáveis.

- Fomentar processos de formação continuada em educação ambiental, formal e não formal, dando condições para a atuação nos diversos setores da sociedade.

- Promover a educação ambiental integrada aos programas de conservação, recuperação e melhoria do meio ambiente, bem como àqueles voltados à prevenção de riscos e danos ambientais e tecnológicos.

- Promover campanhas de educação ambiental nos meios de comunicação de massa, de forma a torná-los colaboradores ativos e permanentes na disseminação de informações e práticas educativas sobre o meio ambiente.

- Criar espaços de debate das realidades locais para o desenvolvimento de mecanismos de articulação social, fortalecendo as práticas comunitárias sustentáveis e garantindo a participação da população nos processos decisórios sobre a gestão dos recursos ambientais.

- Promover a inclusão digital para dinamizar o acesso a informações sobre a temática ambiental, garantindo inclusive a acessibilidade de portadores de necessidades especiais.

- Estimular a cultura de redes de educação ambiental, valorizando essa forma de organização.

- Garantir junto às unidades federativas a implantação de espaços de articulação da educação ambiental.

- Promover e apoiar a produção e a disseminação de materiais didáticopedagógicos e instrucionais.

- Sistematizar e disponibilizar informações sobre experiências exitosas e apoiar novas iniciativas.

Os princípios e objetivos para o desenvolvimento e prática da Educação no país citados acima, bem como os de diversos documentos com princípios e objetivos afins, discorrem em frases bem elaboradas, cerca todos os pontos necessários para que de fato a Educação Ambiental aconteça de forma efetiva no país, porém, muitos pontos demonstram-se fora da realidade socioeducacional brasileira, pois muitos itens ainda não estão presentes na realidade das comunidades e instituições educativas, 
além da falta e do despreparo do profissional. Esse fato é preocupante porque existem princípios e objetivos a serem alcançados, porém os passos para a efetivação dos mesmos são lentos.

\section{CONSIDERAÇÕES FINAIS}

Os princípios e objetivos para o desenvolvimento e prática da Educação no país, bem como os de diversos documentos com princípios e objetivos afins, discorrem em frases bem elaboradas, cerca todos os pontos necessários para que de fato a Educação Ambiental aconteça de forma efetiva no país, porém, muitos pontos demonstram-se fora da realidade socioeducacional brasileira, pois muitos itens ainda não estão presentes na realidade das instituições educativas, além do despreparo do profissional. Esse fato é preocupante porque existem princípios e objetivos a serem alcançados, porém os passos para a efetivação dos mesmos é lento.

Diante do contexto surge a compreensão de que muitas discussões aconteceram e ainda acontecem sobre como desenvolver uma verdadeira educação ambiental. Houve muitos avanços com a origem de documentos relevantes para o assunto e sua prática, porém ainda há muito que fazer. A história não para, continua seu curso e precisamos entender que fazemos parte dessa história e que é preciso atuar de forma responsável diante de todos os segmentos sociais sem jamais esquecer que somos parte desse meio ambiente tão discutido e se não agirmos, no segmento em que estivermos todos esses documentos, princípios e objetivos escritos são em vão.

\section{REFERÊNCIAS}

BRASIL. Ministério do Meio Ambiente. Agenda 21 Brasileira: Resultado da Consulta Nacional. Brasília: MMA, 2002.

BRASIL. Lei no 9795 de 27 de abril de 1999 (Política Nacional de Educação Ambiental).

CARVALHO, Isabel Cristina de Moura. Educação ambiental crítica: nomes e endereçamentos da educação. In: Identidades da Educação Ambiental. Brasília: Ministério do Meio Ambiente, 2004. Disponível em: $\quad$ http://www.scielo.br/scielo.php?script=sci nlinks\&ref=000093\&pid=S0104$4060201400070000900007 \&$ lng=pt. Acesso em: 01 mai. 2019.

FURTADO, Janine Dorneles. Os caminhos da educação ambiental nos espaços formais de ensino-aprendizagem: qual o papel da política nacional de Educação Ambiental? Revista eletrônica 
Mestr. Educ. Ambient., v. 22, jan-jul 2009. Disponível em: https://periodicos.furg.br/remea/article/view/2830. Acesso em: 05 mar. 2019

GADOTTI, M. Saber aprender: um olhar sobre Paulo Freire e as perspectivas atuais da educação. Universidade de Évora: Centro de Referência Paulo Freire, 2000. Disponível em: http://www.acervo.paulofreire.org:8080/ispui/handle/7891/1125. Acesso em: 11 mai. 2019.

GUIMARÃES, Mauro. A dimensão ambiental na educação. Campinas: Papirus, 8 ed. 2007.

GUIMARÃES, Mauro. A formação de educadores ambientais. Campinas: Papirus, 4 ed. 2007.

GUIMARÃES, Mauro. Educação ambiental: no consenso um embate? Campinas: Papirus, 5 ed. 2007

JACOBI, Pedro. Educação e meio ambiente - transformando as práticas. Brasília: Revista brasileira de educação ambiental, 2004.

LAYRARGUES, Philippe Pomier. Identidades da educação ambiental brasileira. Brasília: Ministério do Meio Ambiente, 2004. Disponível em: http://www.mma.gov.br/estruturas/educamb/ arquivos/livro ieab.pdf. Acesso em : 30 abr. 2019.

LAYRARGUES, P. P.; LIMA, G. F. da C. Mapeando as macrotendências político pedagógicas da Educação ambiental contemporânea no Brasil. VI Encontro Pesquisa em Educação Ambiental: Ribeirão Preto, 2011.2 Det. http://www.icmbio.gov.br/educacaoambiental/images/stories/biblioteca/educacao ambiental/Layrargu es e Lima - Mapeando as macro-tend\%C3\%83\%C2\%AAncias da EA.pdf. Acesso em: 15 mai. 2018

LEITE, Valderi D.; SILVA, Monica M. P. da. Estratégias para realização de educação ambiental em escolas do ensino fundamental. Rev. eletrônica Mestr. Educ. Ambient. v. 20, jan-jun 2008.

LOUREIRO, C. F. B. Educar, participar e transformar em educação ambiental. Brasília: Revista brasileira de educação ambiental, 2004

LOUREIRO, C. F. B. O movimento ambientalista e o pensamento crítico: uma abordagem política. Rio de Janeiro: Quartet, 2003a. In: LOUREIRO, C. Trajetória e fundamentos da educação ambiental. São Paulo: Cortez, 2004.

LOUREIRO, C. F. B. Premissas teóricas para uma educação ambiental transformadora. Ambiente e Educação, Rio Grande, 2003.

RUIZ, J. B.; Leite et al. Educação Ambiental e os Temas Transversais. Akrópolis, p.31-38, 2005.

SEARA FILHO,G. Apontamentos de introdução à educação ambiental. Revista

Ambiental, ano 1, v. 1, p. 40-44, 1987. In: MARCATTO, Celso. Educação ambiental: Conceitos e princípios. Belo Horizonte: FEAM, 2002. 